\title{
HISTÓRIA EM QUADRINHOS E HISTÓRIAS DE VIDA DE PROFESSORAS TRANS: EMERGÊNCIAS TEMÁTICAS NO CONPEDI
}

\section{Renato Duro Dias ${ }^{1}$}

\section{Resumo:}

O presente artigo discute histórias de vida de professoras trans tendo como elemento de análise a arte sequencial a partir da história em quadrinhos Minha professora é trans. E daí? (DE MAIO, 2015). De abordagem qualitativa, a proposta investigativa avança sobre estudos com imagens e discursos, explorando a produção acadêmica publicada pelo CONPEDI sobre a temática trans. Trata-se de debate emergente em muitos campos do conhecimento. $\mathrm{O}$ referencial teórico parte de narrativas de vida de professoras transexuais ambientadas em suas experiências na docência. Espera-se que esta pesquisa interdisciplinar possibilite aprofundar os diálogos existentes entre arte e direito.

Palavras-chave: Arte, Direito, História em quadrinhos, Trans, Transexual.

\section{COMICS AND LIFE STORIES OF TRANS TEACHERS: THEMATIC: EMERGENCIES IN CONPEDI}

\begin{abstract}
:
This article discusses life stories of trans teachers having as an element of analysis the sequential art from comics Minha professora é trans. E daí? (DE MAIO, 2015). With a qualitative approach, the investigative proposal advances on studies with images and speeches, exploring the academic production published by CONPEDI on the trans thematic. This is an emerging debate in many fields of knowledge. The theoretical framework starts from the life narratives of transsexual teachers based on their experiences in teaching. It is hoped that this research interdiscipinar will make it possible to deepen the existing dialogues between art and law.
\end{abstract}

Keywords: Art, Law, Comics, Trans, Transsexual.

\section{INTRODUÇÃO}

O presente artigo discute histórias de vida de professoras trans $^{2}$ tendo como

\footnotetext{
${ }^{1}$ Pró-Reitor de Graduação da Universidade Federal do Rio Grande (FURG) vinculado a esta universidade como Professor da Faculdade de Direito, da Especialização em Educação em Direitos Humanos e do Programa de PósGraduação em Direito - Mestrado em Direito e Justiça Social. É Doutor em Educação com período de doutoramento sanduíche na Universidade de Lisboa, Portugal. É Vice-líder do Laboratório Imagens da Justiça Grupo de Pesquisa do CNPq.

2 O termo "trans" será utilizado ao longo desta investigação para designar "as vivências que extrapolam a naturalização dos corpos, a biologização das identidades, o binarismo dos gêneros e os enquadramentos classificatórios, especificadamente as experiências travestis e transexuais" (LIMA, 2014, p.38).
} 
elemento de análise a arte sequencial a partir da história em quadrinhos Minha professora é trans. E daí? (DE MAIO, 2015). Contemporaneamente os usos de histórias em quadrinhos têm servido como importante dispositivo de comunicação, palavras e imagens (EISNER, 2001, 2005). Servem para abordar variados gêneros, da ficção ao não ficcional. Do campo das artes às linguagens, as $\mathrm{HQs}^{3}$, sejam impressas ou em produções cinematográficas, continuam influenciando gerações.

De abordagem qualitativa, a proposta investigativa avança sobre os estudos com imagens e discursos, explorando a produção acadêmica ${ }^{4}$ publicada pelo Conselho Nacional de Pesquisa e Pós-Graduação em Direito (CONPEDI) sobre a temática trans. Trata-se de debate emergente em muitos campos do conhecimento, especialmente, direito (direitos humanos), sociologia, filosofia e arte. Como se pode perceber da pesquisa exploratória aqui apresentada, são múltiplas áreas, referenciais e métodos que dialogam sobre estes estudos, o que caracteriza o enfoque interdisciplinar.

O referencial teórico parte de narrativas de vida de professoras transexuais ambientadas em suas experiências na docência e em suas pesquisas acadêmicas. Assim, o estudo pretende dar voz as trajetórias vividas por estas professoras, procurando respeitar o lugar de fala. "Pensar lugar de fala seria romper com o silêncio instituído para quem foi subalternizado, um movimento no sentido de romper com a hierarquia" (RIBEIRO, 2017, p. 50). No entanto, isto não significa afirmar que não se possa dialogar com (falar com)

Se, na sua origem, a ideia de lugar de fala podia ser entendida como um chamamento à abertura do debate para a integração de múltiplas vozes silenciadas, agora o "lugar de fala" muitas vezes serve como ferramenta de censura e exclusão. [...]

No momento em que o retrocesso se alastra pelo mundo afora, prejudicando tantos grupos de pessoas em tantas dimensões, e em que é tarefa urgente construir uma resistência também pluridimensional, o particularismo estreito e estridente dessa percepção rasa do "lugar de fala" torna-se, sem dúvida, um aliado da permanência da dominação. (MIGUEL, 2019).

Como principais questões de pesquisa têm-se: como a arte sequencial a partir da história em quadrinhos Minha professora é trans. E daí? pode contribuir para ampliar o reconhecimento de direitos de professoras transexuais? Quais as possíveis relações entre arte,

\footnotetext{
${ }^{3}$ Como são popularmente conhecidas as histórias em quadrinhos.

${ }^{4}$ Para tal foi feito uma exploratória sobre a produção na temática trans nos Anais dos Encontros e Congressos do CONPEDI nos últimos seis (06) anos.
} 
cultura visual, direito e conhecimento interdisciplinar? Como imagens e, especialmente, histórias em quadrinhos não ficcionais podem transpor e desvelar a realidade destas sujeitas imvisibilizadas?

Para responder estes questionamentos, primeiramente, apresenta-se uma pesquisa exploratória com alguns dados sobre o "estado da arte" da temática trans nas publicações do CONPEDI no período de 2014 a 2019. Num segundo momento, a partir da história em quadrinhos Minha professora é trans. E daí?, discute-se a vivência de uma professora trans, procurando traçar alguns elementos conceituais sobre HQs. Diante destes elementos de arte sequencial, na terceira parte, debruça-se sobre os contextos de docentes trans, tendo como referência suas produções acadêmicas (ANDRADE, 2002, REIDEL, 2013, LANZ, 2014, OLIVEIRA, 2017). Ao fim, apontam-se as considerações finais.

Desta forma, com base nestas reflexões e nas histórias de vida aqui narradas, esperase que esta pesquisa possibilite aprofundar os diálogos interdisciplinares existentes entre arte e direito, bem como desvelar o direito ao reconhecimento identitário de pessoas trans.

\section{A EMERGÊNCIA DA TEMÁTICA TRANS NO CONPEDI}

Gradativamente a produção acadêmica na área do Direito tem aberto portas para o que poderia ser denominado de temáticas emergentes. Elas envolvem, por exemplo, o estudo dos novos direitos, os avanços tecnológicos e suas interfaces com o saber jurídico, as variadas formas de gerir as relações privadas em redes sociais, os artefatos artísticos contemporâneos e suas implicações com a ciência jurídica.

As múltiplas vivências identitárias, sejam elas culturais, sexuais e de gênero, também reverberam em campos científicos dos mais variados. $\mathrm{O}$ direito não foge a regra e o CONPEDI como importante repositório dos debates emergentes tem sido um lócus privilegiado para o aprofundamento destes temas em que se paute a interdisciplinaridade ${ }^{5}$.

O que com isso queremos dizer é que o pensar interdisciplinar parte do princípio de que nenhuma forma de conhecimento é em si mesma racional. Tenta, pois, o diálogo

\footnotetext{
${ }^{5}$ Traduzido livremente: “O conceito de interdisciplinaridade se situa sobre o plano (nível) epistemológico, o qual se pode considerar que se refere à cooperação de diversas disciplinas, que contribuem para uma compreensão comum e, por associação, permitem o surgimento e o desenvolvimento de novos conhecimentos (saberes)". (UNESCO, 1986) Disponível em: https://en.unesco.org/themes/education/ . Acesso em: 12 abr. 2020.
} 
com outras formas de conhecimento, deixando-se interpenetrar por elas. Assim, por exemplo, aceita o conhecimento do senso comum como válido, pois é através do cotidiano que damos sentidos às nossas vidas. (FAZENDA, 2009, p. 17).

Para este estudo apresentam-se alguns elementos que indicam como as temáticas trans tem sido objeto de análise de muitas investigações, inclusive com ênfase nas relações entre direito, arte e literatura (DIAS, 2015). Ao realizar pesquisa exploratória ${ }^{6}$ (de 2014 a 2019) no site $^{7}$ do CONPEDI percebe-se o conjunto destas publicações.

Logo de partida o que salta aos olhos é a grande quantidade de trabalhos apresentados no ano de 2017. Foram vinte e quatro (24) trabalhos, contabilizando trinta e seis por cento $(36 \%)$ do número total analisado. Pode-se perceber que nos dois primeiros anos de análise (2014 e 2015) a quantidade de trabalhos apresentados em eventos do CONPEDI era ainda pequena (dois trabalhos em cada ano).

Tabela 1 - Trabalhos apresentados e publicados pelo CONPEDI ${ }^{8}$.

\begin{tabular}{ccc}
\hline Ano de Publicação & $\mathbf{N}^{\mathbf{0}}$ de Publicações & \% \\
\hline $\mathbf{2 0 1 9}$ & 19 & $29 \%$ \\
$\mathbf{2 0 1 8}$ & 14 & $21 \%$ \\
$\mathbf{2 0 1 7}$ & 24 & $36 \%$ \\
$\mathbf{2 0 1 6}$ & 05 & $08 \%$ \\
$\mathbf{2 0 1 5}$ & 02 & $03 \%$ \\
$\mathbf{2 0 1 4}$ & 02 & $03 \%$ \\
\hline
\end{tabular}

Fonte: Elaborada ${ }^{9}$ com base no CONPEDI (2020).

Nos anos de 2016, 2018 e 2019, é possível notar um aumento substancial na apresentação de pesquisas, chegando aos dezenove (19) trabalhos apresentados em 2019 com um percentual de $29 \%$ do total. Contudo, como dito anteriormente, a maior diferença é vista

\footnotetext{
${ }^{6}$ A pesquisa exploratória utilizou como parâmetros de busca a utilização dos descritores (termos) "trans", "transexual" e "transgênero". Os descritores foram mapeados a partir dos títulos, resumos e palavras-chave das publicações.

${ }^{7}$ Disponível em: https://www.conpedi.org.br/ Acesso em: 12 abr. 2020.

${ }^{8}$ Trabalhos apresentados e publicados Anais dos Congressos e Encontros nacionais e internacionais do CONPEDI no período compreendido entre os anos de 2014 e 2019. Disponível em: https://www.conpedi.org.br/ Acesso em: 12 abr. 2020.

${ }^{9}$ As tabelas e quadros desta investigação foram elaborados com apoio de Bolsista de Iniciação Científica (PROBIC CNPq). Fica registrado o agradecimento especial ao bolsista, bem como ao financiamento pelo Conselho Nacional de Desenvolvimento Científico e Tecnológico - CNPq.
} 
entre a produção de artigos de 2016 para 2017, cujo aumento é de 19 trabalhos, um aumento percentual de vinte e oito por cento (28\%) do total de trabalhos presentes nas publicações do CONPEDI.

Outro aspecto relevante das produções levantadas está relacionado ao percurso metodológico escolhido pelos/as autores e autoras destas investigações. Com relação às metodologias utilizadas, fez-se uma pesquisa por descritores junto aos resumos e introduções dos próprios trabalhos para formar o banco de dados que será expresso na forma de tabela e gráfico a seguir. Para tanto, foi utilizado o critério de vincular os termos encontrados nos trabalhos aos conceitos que os próprios autores e autoras tomaram por metodologia, por mais que alguns sejam tidos, a rigor, por métodos.

Disso, vê-se que a "pesquisa bibliográfica" ${ }^{10}$ é a modalidade que vincula quase a metade dos trabalhos apresentados, trinta e dois (32) trabalhos, somando um total de cinquenta por cento (50\%). Seguido das modalidades "dedutivo" e "jurídico-sociológico" com dez (10) e sete (07) estudos, vale dizer, quinze por cento (15\%) e onze por cento (11\%), respectivamente, do total de trabalhos apresentados nos eventos do CONPEDI.

Tabela 2 - Metodologias utilizadas nos trabalhos apresentados e publicados pelo CONPEDI.

\begin{tabular}{ccc}
\hline Metodologias & $\mathbf{N}^{\mathbf{0}}$ de Trabalhos & $\%$ \\
\hline Pesquisa Bibliográfica & 33 & $50 \%$ \\
Dedutivo & 10 & $15 \%$ \\
\hline Jurídico-Sociológico & 07 & $11 \%$ \\
Hipotético-dedutivo & 06 & $09 \%$ \\
Histórico-crítica & 03 & $05 \%$ \\
Estudo de Caso & 03 & $05 \%$ \\
Indutivo & 02 & $03 \%$ \\
Dialético & 01 & $01 \%$ \\
\hline Pesquisa Exploratória & 01 & $01 \%$ \\
\hline
\end{tabular}

Fonte: Elaborada com base no CONPEDI (2020).

Das investigações analisadas neste recorte e publicadas pelos Anais dos eventos do

\footnotetext{
${ }^{10}$ Aqui se vê os usos das expressões revisão bibliográfica e revisão de literatura também sendo utilizados como "pesquisa bibliográfica".
} 
CONPEDI percebe-se um influente avanço nos estudos sobre gênero, feminismos, teoria feminista e sexualidades, produções estas com uso preponderante de autoras (mulheres).

Tabela 3 - Principais autoras referenciadas na bibliografia.

\begin{tabular}{ccc}
\hline Autora & $\mathbf{N}^{\mathbf{0}}$ de Citações & \% \\
\hline Berenice Bento & 30 & $23 \%$ \\
Judith Butler & 21 & $16 \%$ \\
Maria Berenice Dias & 13 & $10 \%$ \\
Maria Helena Diniz & 11 & $9 \%$ \\
Jaqueline Gomes de Jesus & 08 & $6 \%$ \\
Maria Tereza Fonseca & 07 & $5 \%$ \\
Simone de Beauvoir & 06 & $4 \%$ \\
Joan Scott & 05 & $2 \%$ \\
Nancy Fraser & 05 & $2 \%$ \\
\hline
\end{tabular}

Fonte: Elaborada com base no CONPEDI (2020).

Tabela 4 - Principais campos teóricos articulados pelas autoras referenciadas.

\begin{tabular}{|c|c|}
\hline Autoras & Campos \\
\hline Berenice Bento & Feminismo, Gênero, Sexualidade e Direitos Humanos. \\
\hline Judith Butler & Feminismo, Teoria Queer, Filosofia política, Arte e ética. \\
\hline Maria Berenice Dias & Direito de família, Direito da mulher e Direitos homoafetivos. \\
\hline Maria Helena Diniz & Direito: Direito Civil \\
\hline Jaqueline Gomes de Jesus & Identidade de gênero, Direitos Humanos e Diversidade Sexual. \\
\hline Maria Tereza Fonseca Dias & Teoria do Direito, Metodologia da Pesquisa Jurídica. \\
\hline Simone Beauvoir & Filosofia, Feminismo e Existencialismo. \\
\hline Joan Scott & História, Feminismo e Gênero. \\
\hline Nancy Fraser & Filosofia, Feminismo, Teoria Crítica e Justiça. \\
\hline
\end{tabular}

Fonte: Elaborada com base no CONPEDI (2020).

Para se auferir a representatividade de temáticas abordadas, buscou-se classificar os trabalhos apresentados nos eventos do CONPEDI em quatro (04) grandes grupos: a) Reconhecimento da identidade de gênero de pessoas trans; b) Preconceito/violência contra pessoa trans; c) Alteração do nome (nome social) e d) Políticas públicas destinadas às pessoas trans. Com relação a estes grupos se pode observar que quarenta por cento (40\%) do total de 
trabalhos apresentados tratavam do reconhecimento da identidade de gênero das pessoas trans, ou seja, vinte e sete (27) pesquisas. Sendo quatro (04) especificamente sobre o reconhecimento da identidade de mulheres trans e quatro (04) para abordagens às crianças trans.

Gráfico 1 - Temáticas trans abordadas nos trabalhos apresentados e publicados pelo CONPEDI.

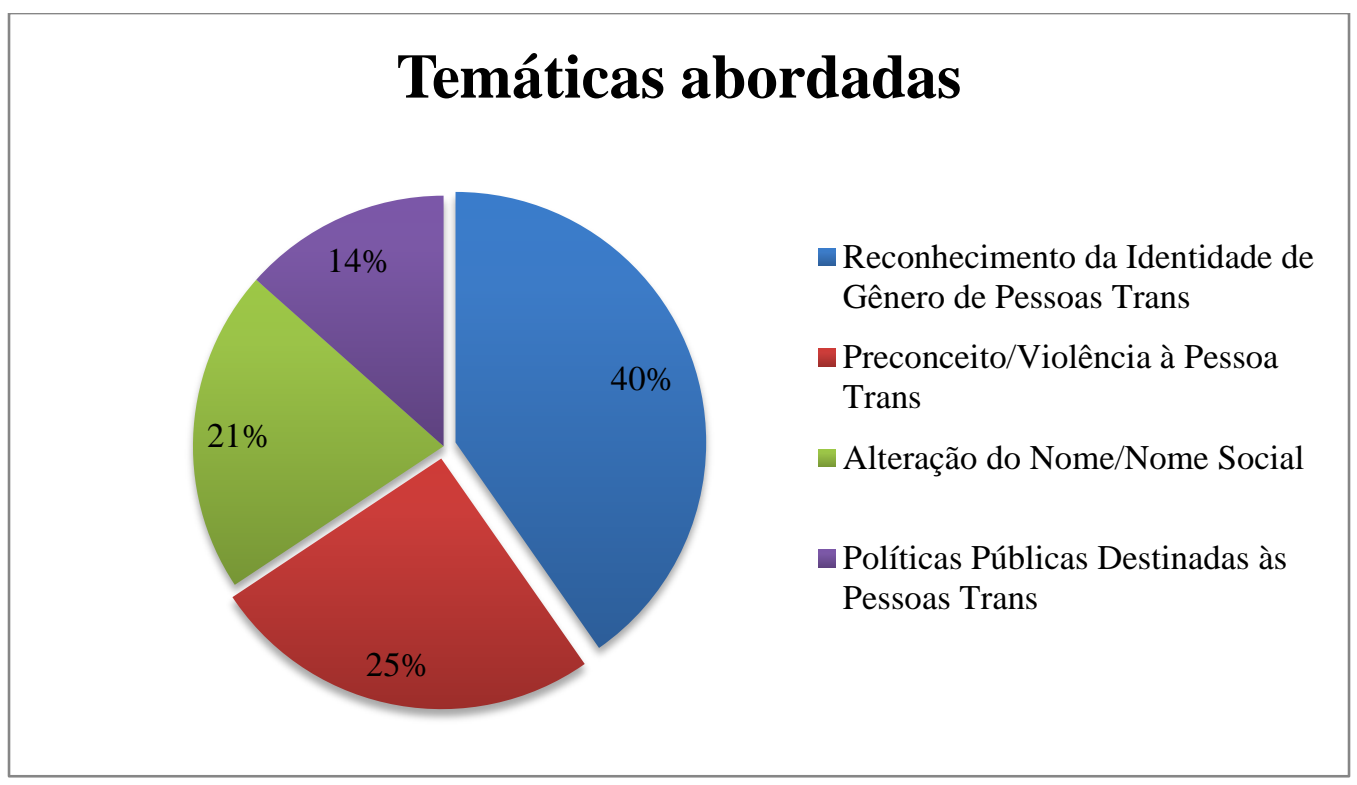

Fonte: Elaborado com base no CONPEDI (2020).

Por último, buscou-se contabilizar as palavras-chaves dos trabalhos apresentados no CONPEDI sobre a temática trans. Para tal, foram agrupadas as palavras mais frequentes [aqui se refere as cinco (05) mais usadas] em ordem decrescente, da mais citada até a menos citada.

Outro fator que merece atenção é a porcentagem que aparece na terceira coluna da tabela que segue. Esse valor relaciona o número de citações, ou seja, o número de trabalhos em que a palavra-chave é citada, portanto o número de trabalhos em que o descritor trans aparece é relevante, aproximadamente setenta (70) no conjunto dos trabalhos aqui analisados (CONPEDI, 2014-2019).

Tabela 5 - Principais palavras-chave utilizadas. 


\begin{tabular}{ccc}
\hline Palavras-chave & $\mathbf{N}^{\mathbf{0}}$ de Citações & $\begin{array}{c}\text { \% com Relação ao } \mathbf{N}^{\mathbf{0}} \text { Total de } \\
\text { Trabalhos }\end{array}$ \\
\hline Gênero & 26 & $39 \%$ \\
Transexualidade & 19 & $29 \%$ \\
Trans & 17 & $26 \%$ \\
Identidade de gênero & 15 & $23 \%$ \\
Transexual & 13 & $20 \%$ \\
\hline
\end{tabular}

Fonte: Elaborado com base no CONPEDI (2020).

O que o conjunto de dados desta pesquisa exploratória revela é a emergência da temática trans nos artigos apresentados e nas publicações dos Anais do CONPEDI. Como se pode perceber, a cada ano se amplia o número de investigações na área. Tais elementos apontam a importância que o campo das ciências jurídicas e os entrecruzamentos interdisciplinares dão às identidades trans. Razão para problematizar este diálogo interdisciplinar entre arte e direito.

\section{MINHA PROFESSORA É TRANS. E DAÍ?}

A história em quadrinhos Minha professora é trans. E daí? de Alexandre de Maio (2015) conta a uma história de Luiza, uma transmulher branca, de classe média, graduada em Filosofia que trabalha a aproximadamente quinze (15) anos como professora no ensino médio. A HQ é do gênero não ficcional, pois se baseia em uma história de vida real.

A história de Luiza é uma exceção às narrativas da grande maioria das pessoas trans. Sejam trans mulheres [pessoa que foi atribuída ao sexo (biológico) - gênero masculino ao nascer e que possui uma identidade de gênero feminina], ou seja, um homem trans [pessoa que foi designada ao sexo (biológico) - gênero feminino ao nascer e que possui uma identidade de gênero masculina] a trajetória de vida lhes espera é a abjeção, o preconceito e a discriminação. Utiliza-se destes referenciais binários ${ }^{11}$, embora se entenda como Bento (2014, p. 51)

A noção de humanidade que nos constitui requer a categoria de gêneros e este só é reconhecível, só ganha vida e adquire inteligibilidade, segundo as normas de gênero, em corpos-homens e corpos-mulheres. Ou seja, a reivindicação última das pessoas

\footnotetext{
${ }^{11}$ A visão binária somente compreende as existências humanas em homem e mulher.
} 
trans é pelo reconhecimento social de sua condição humana.

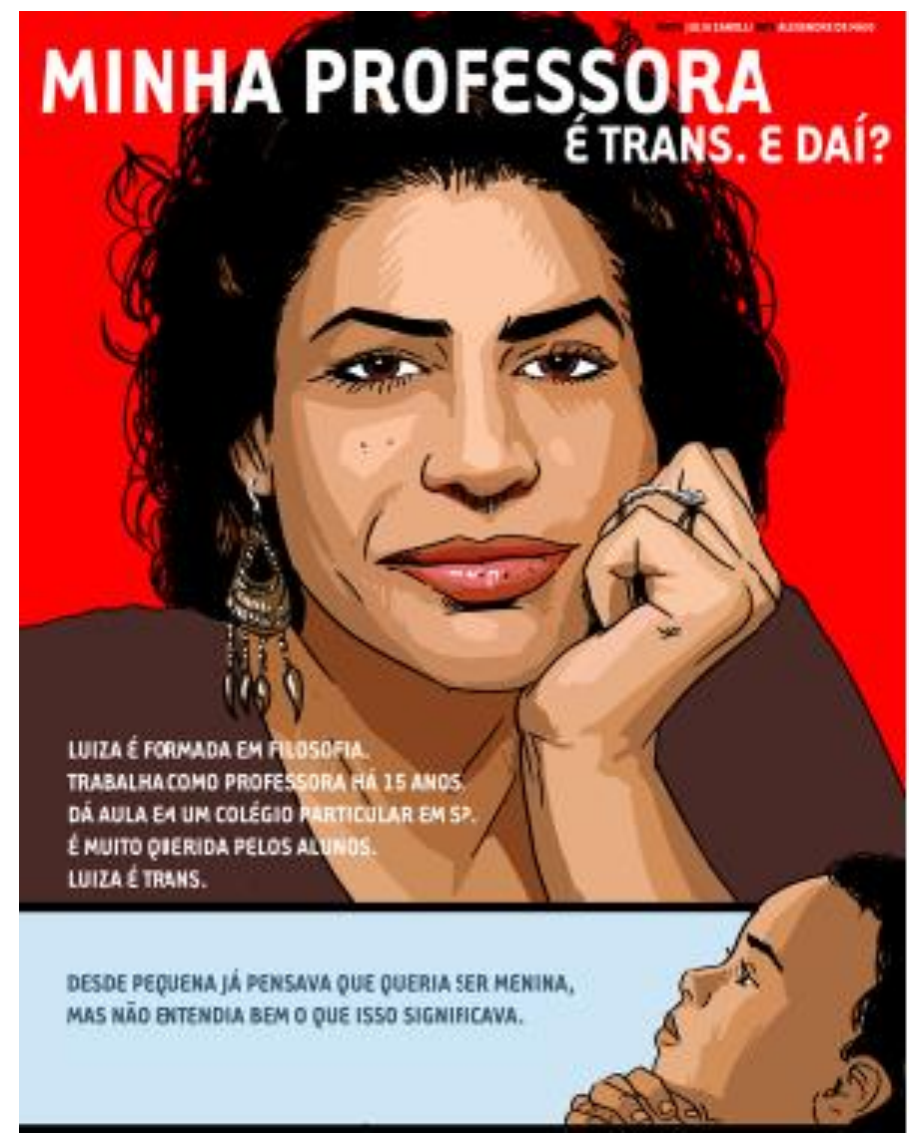

Fonte: Alexandre De Maio (2015). ${ }^{12}$

Como professora, Luiza também sofreu preconceito, tendo sido demitida (e logo depois readmitida em ação judicial) por uma escola privada em função de sua identidade de gênero. Para mostrar que algumas dessas histórias de vida podem ter um final diferente, os alunos de Luiza participaram de entrevistas e contribuíram para a criação da história em quadrinhos aqui veiculada Minha professora é trans. E daí?.

A HQ começa contando os questionamentos e as inquietações de Luiz ${ }^{13}$ sobre sua identidade de gênero e sexual, e sua partilha com os/as estudantes em sala de aula. Nesse

\footnotetext{
${ }^{12}$ Disponível em: https://alexandredemaio.com.br/minha-professora-trans-e-dai-catraca-livre Acesso em: 17 abr. 2020.

${ }^{13}$ Nome civil (registro de nascimento).
} 
percurso, a primeira etapa foi a negação (ou a necessidade de bloqueio dos desejos) sobre sua identidade de gênero feminina. Logo a conversa com colegas professores/as, direção, e ao final com a classe foram marcados de angústia e medo.

Imagem 2 - Detalhe da HQ Minha professora é trans. E daí?

(DE MAIO, 2015)

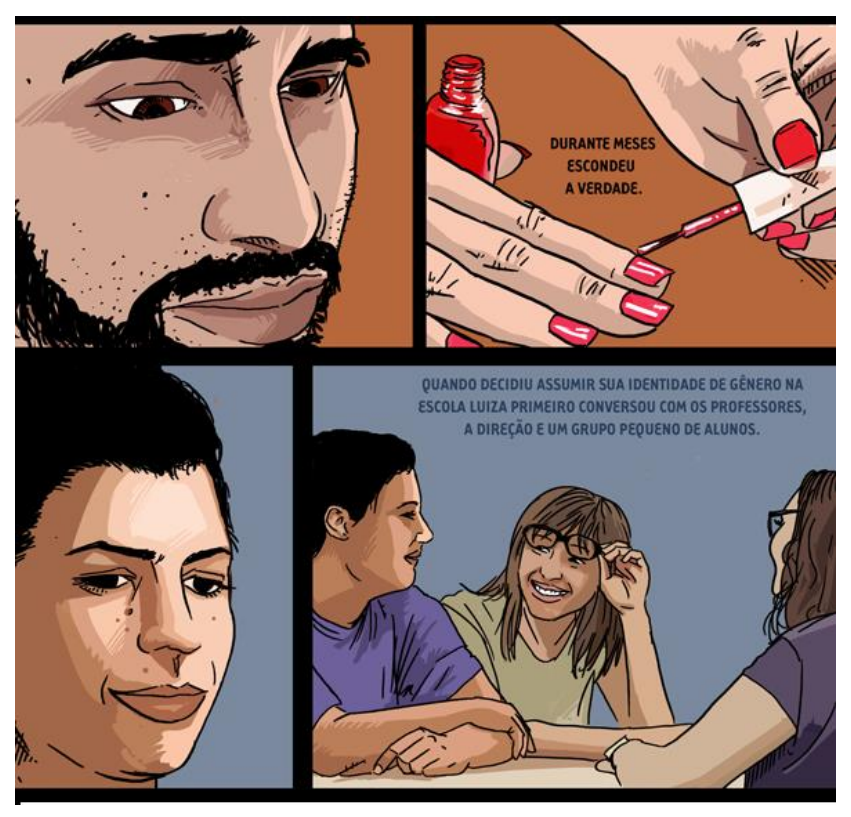

Fonte: Alexandre De Maio (2015).

Segundo Luiza, o momento não foi fácil. Muitos apoiaram a tomada de decisão, mas alguns pais e alunos/as pediram sua demissão. O fato é que a revelação em plena escola trouxe a baila importantes temas (machismo, sexismo e gênero).

Imagem 3 - Detalhe da HQ Minha professora é trans. E daí?

(DE MAIO, 2015) 


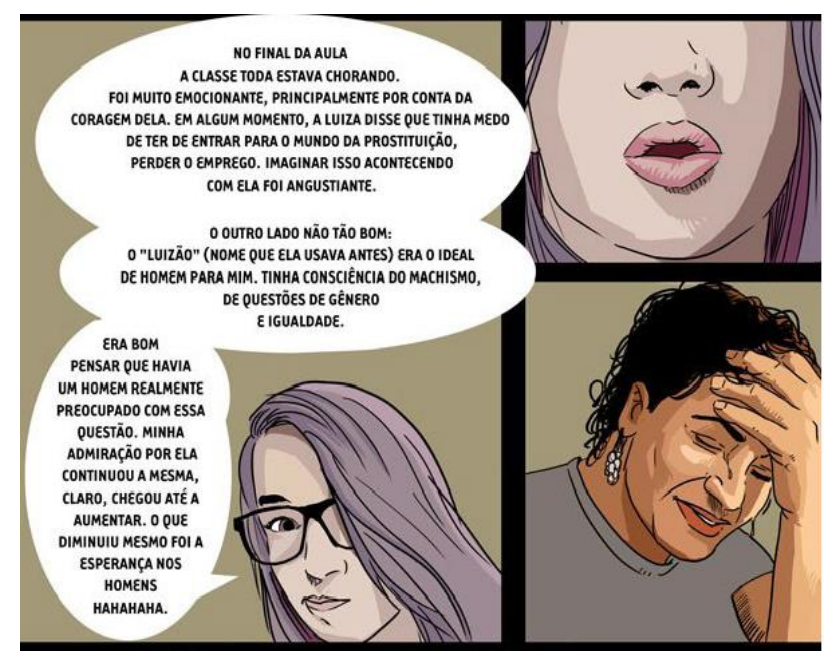

Fonte: Alexandre De Maio (2015).

Os quadrinhos representam e traduzem essas imagens de nervosismo, sentimentos de dúvida e de conflito narrados por Luiza em seus contatos diários dentro da escola em que trabalhava. As representações imagéticas falam por si só.

Em resumo, as formações imaginárias, presentes em todos os processos discursivos, inclusive nas histórias em quadrinhos não ficcionais, são caracterizadas como um jogo de imagens que os sujeitos interlocutores fazem de si, do outro e do objeto a que se refere no processo de produção do discurso. (TAVARES, 2014, p. 39).

Assim, estes objetos artísticos sequenciais possibilitam manejam textos, discursos e imagens relacionando-os ao cotidiano de quem narra e daquele ou daquela história que é narrada. As HQs refletem, portanto, uma diversidade de produções discursivas e visuais, veículo no qual se tematizam contestações, ideologias, sentimentos e ambivalências próprias do fazer artístico.

\begin{abstract}
A função fundamental da arte dos quadrinhos, que é comunicar ideias e/ou histórias por meio de palavras e figuras, envolve o movimento de certas imagens (como pessoas e coisas) no espaço. Para lidar com a captura ou o encapsulamento desses eventos no fluxo da narrativa, eles devem ser decompostos em segmentos sequenciados. Esses segmentos são chamados quadrinhos. (EISNER, 2010, p. 39).
\end{abstract}

De acordo com Eisner (2010), a história em quadrinhos data do final do século XIX, surgindo como uma prática de arte em sequência (especialmente elaborada em "tiras") que continha, em sua grande maioria um tom satírico ou de crítica social. Na primeira metade do século XX as HQs ganham cores e dialogam com a produção e divulgação de super-heróis, nestes termos, pode-se afirmar que o caráter ficcional começa a ser um potente espaço de 
criação artístico-literária nas HQs.

O crescimento das HQs implicou na ampliação das formas de impressão. Iniciadas nos jornais e periódicos de larga circulação, elas passam a se transformam em narrativas cada vez mais complexas, envolvendo um contingente importante de profissionais, tais como: editores, desenhistas, coloristas, diagramadores dentre outros.

O não verbal, as imagens, possuem grande importância na leitura e na abordagem teórica das HQs, porque é por meio dos elementos gráficos, da narrativa gráfica, que há também a construção dos efeitos de sentidos almejados, o que confere aos quadrinhos sua peculiaridade frente a outros gêneros como o romance, o artigo de opinião, a carta, a crônica, dentre outros, que utilizam predominantemente a linguagem verbal, as palavras. (TAVARES, 2014, p. 69)

Por ser um ato que envolve interpretação estética e compreensão de texto, a leitura das HQs torna-se desafiadora, o que pode produzir uma ambivalência, de um lado estimulando o interesse pela narrativa enigmática e, de outro, um afastamento pela complexidade de códigos interpretativos a serem manejados.

Para Tavares (2014, p. 87-88), essa ambivalência também está presente quando se refere ao trato temático das histórias em quadrinhos do tipo não ficcionais.

\footnotetext{
Em outros termos, veicular temática de cunho político e social, com o auxílio das histórias em quadrinhos, ocasiona em uma tentativa de expor "didaticamente" assuntos com grande visibilidade e importância social, que pode, por vezes, ser pouco ou não compreendido pelos leitores, pelos cidadãos. Contudo, essa assertiva também faz irromper outras possibilidades: será uma forma de subestimar a capacidade de leitura do leitor comum; será uma forma de tratar um assunto sério e dar aparência de algo irreal e ficcional; será uma forma de dizer qual dito deve ser compreendido como verídico; quais os aspectos valorativos que irrompem desse uso.
}

Essa possibilidade revelada por Tavares (2014) joga luzes sobre a proposta de De Maio (2015), dar visibilidade e produzir reflexão sobre histórias de vida de professoras trans. Além do mais, quando um quadrinista se dispõe a tratar sua obra a partir de relatos de estudantes, sabe-se que sua HQ surgirá como um elemento de intrincadas narrativas que circularam por espaços até então inimaginados, como a escola e a família. Essas práticas discursivas em contextos coletivos podem possibilitar descobertas e afloramentos necessários para vivências de gênero e das sexualidades. 


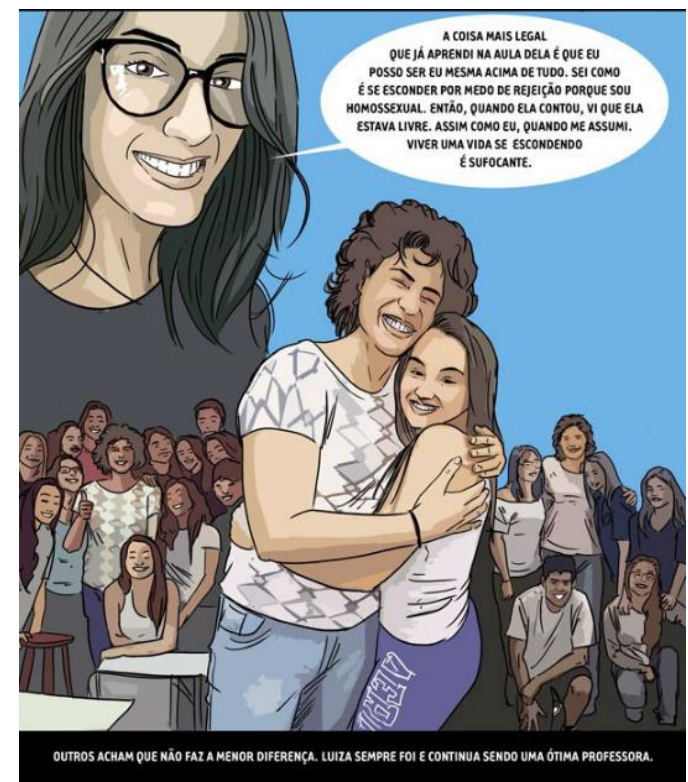

Fonte: Alexandre De Maio (2015).

\title{
4. HISTÓRIAS DE VIDA TRANS - PERCURSOS DOCENTES
}

Segundo dados do Dossiê dos assassinatos e da violência contra travestis e transexuais (BENEVIDES e NOGUEIRA, 2020, p. 03), da Associação Nacional de Travestis e Transexuais do Brasil (ANTRA) Instituto Brasileiro Trans de Educação (IBTE), o Brasil é o país com maior número de assassinatos de transexuais na América Latina.

\begin{abstract}
As mortes de travestis e transexuais continuam subnotificadas. No Brasil, $90 \%$ das travestis e mulheres transexuais ainda vivem da prostituição que, em maioria, acontece nas ruas, exposição que aumenta ainda mais a vulnerabilidade diante das inúmeras violências físicas e psicológicas a que são submetidas, e que resultam em mortes, muitas vezes.
\end{abstract}

Poucas são as pessoas trans que conseguem concluir o ensino fundamental e médio, mais escassos os casos daquelas e daqueles que chegam à universidade e tem possibilidade de colar grau em um curso de educação superior.

Torna-se imprescindível que o Estado intervenha de maneira a diminuir essa discriminação violenta sofrida por nosso grupo populacional e que leva ao extermínio de nossos corpos. Faz-se necessário oferecer condições dignas de educação, trabalho, moradia e qualidade de vida. O princípio da dignidade da pessoa e os direitos humanos garantem a proteção da integridade física e moral, da privacidade e do próprio corpo. Isso requer uma ação estatal para que essa população possa usufruir desses direitos garantidos na Declaração Universal dos Direitos Humanos. (BENEVIDES e NOGUEIRA, 2020, p. 63). 
As histórias de vida aqui narradas tratam de reafirmar a necessidade de ampliar as condições de acesso e mitigação de desigualdades para que esse conjunto de pessoas alcance de alguma maneira condições de empregabilidade razoáveis, que possibilitem dar continuidade a seus estudos (sejam em que nível desejar), além da garantia de políticas públicas de saúde, de enfrentamento à violência sistemática pelas quais são diariamente passam.

Assim, nesta etapa do estudo, abrir-se-á um diálogo com Marina Reidel (2013), Luma Nogueira de Andrade (2002), Letícia Lanz (2014) e Megg Rayara Gomes de Oliveira (2017) para que a partir destas narrativas docentes e produções acadêmicas firme-se um compromisso em escutar, dialogar com e falar junto destas autoras.

\footnotetext{
Dar nome e definir a identidade de gente como eu implica em mexer - e mexer profundamente - no imenso castelo social que está erguido sobre o dispositivo binário de gênero e que dele depende para continuar de pé. Por colocar em risco esse mesmo dispositivo, ameaçando a estabilidade de toda a imensa estrutura da sociedade em que vivemos gente igual a mim tem sido considerada infratora da ordem social e tratada como _doente mental', perversa ou depravada. É sobre essa gente que eu vou falar; é a essa gente, à qual eu pertenço, que eu desejo dar voz. (LANZ, 2014, p. 12).
}

Reivindica-se, assim, a postura do que poderia se denominar de uma intelectualidade pós-colonial, que cria espaços que sejam meios pelos quais o subalterno/a possa falar e para que seja ouvida enquanto fala ${ }^{14}$.

Imagem 5 - Detalhe da HQ Minha professora é trans. E daí?

(DE MAIO, 2015)

\footnotetext{
${ }^{14}$ Para detalhamento de o tema ver Spivak (2014).
} 


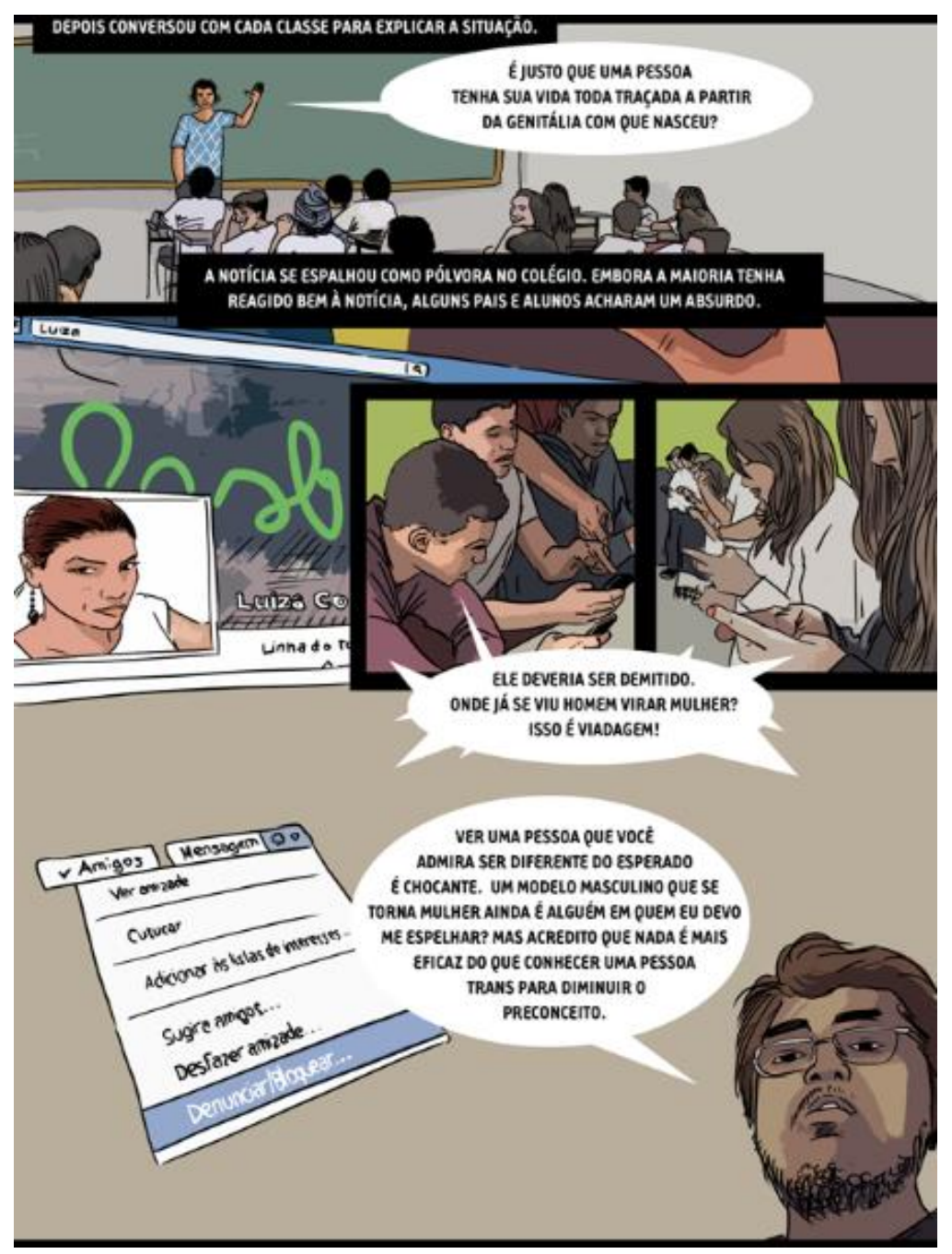

Fonte: Alexandre De Maio (2015).

[...] desde criança sofro com a imposição e segregação dos comportamentos determinados para alunos (as) dos sexos masculino e feminino. Na escola, fui violentamente castigada física e verbalmente quando buscava qualquer tentativa de cruzamento da linha de fronteira que separa o sexo masculino do feminino. A vigília era constante nas brincadeiras, nos brinquedos utilizados, nos gestos. [...]

Vivenciei e vivencio em minha história de vida o estar travesti como aluna e professora da educação básica e ensino superior, e ratifico que para chegar até aqui foi necessário penetrar nas regras do jogo disciplinar e normativo da escola e da sociedade, a fim de criar [...] de uma situação de marginalidade perpétua, mesmo que muito bem vigiada, preparada a todo instante para receber punição. Aprendi desde muito cedo que o menor dos meus erros poderia ser desculpa para uma retaliação. (ANDRADE, 2002, p. 19-20).

Em sua tese Andrade (2002, p, 15) objetiva "apresentar as travestis no espaço escolar, desvendando suas sociabilidades, resistências e assujeitamentos à ordem normativa, partindo de suas próprias narrativas". A partir de uma escuta atenta Andrade (2002) percebe 
um conjunto de trajetórias em que a cumplicidade do cotidiano com atos de violência, silêncio e abjeção se tornam parte de uma recorrente e visivelmente aterrorizante história de vida.

Imagem 5 - Detalhe da HQ Minha professora é trans. E daí?

(DE MAIO, 2015)

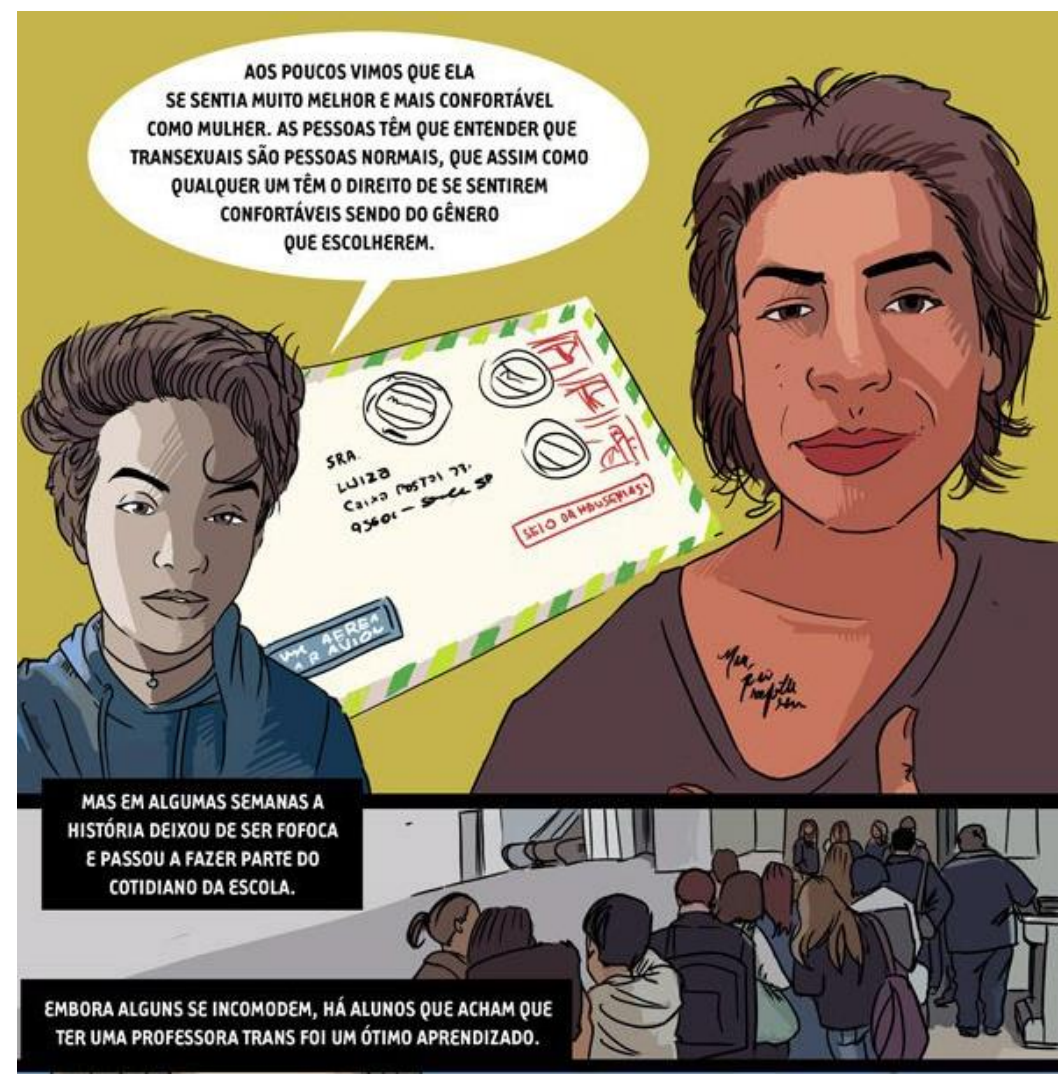

Fonte: Alexandre De Maio (2015).

Vejo pelas experiências e vivências profissionais que a escola precisa ser reinventada, questionada, sexualizada e quem sabe "trans-formada": uma escola alicerçada em direitos e deveres humanos. Uma pedagogia do salto alto provoca um mal estar no conservadorismo e no tradicionalismo desta escola criada para um determinado público, muito além da realidade de hoje. Imagino que esta pedagogia possa, sim, através da postura ética, dar conta de atender uma demanda voltada para o social, retomando o sentimento e a essência dos alunos que precisam reaprender valores e novos conceitos. Esta forma de ensinar, trazendo professores transexuais e travestis para a sala de aula, poderá torná-los, assim como outros tantos professores heterossexuais, adultos de referência. (REIDEL, 2013, p. 50).

As narrativas pessoais e profissionais das professoras trans revelam como a escola, que é reflexo e produto das mais variadas formas de violência e opressão em sociedade, continua sendo um espaço ambivalente de disputa de discursos e de relações de poder. Esses relatos desvelam o quanto é necessário avançar em termos de políticas de igualdade de gênero 
e de liberdade de designação sexual dentro dos espaços educativos.

Por isso, propostas como a Pedagogia de Salto Alto (REIDEL, 2013) podem ser uma práxis possível para se reinventar o lugar da escola. "Propor uma pedagogia do salto alto é provocar inquietações e conflitos trazendo personagens que, de uma forma ou outra, poderão ser formadores e adultos de referência.” (REIDEL, 2013, p. 48).

Não é diferente o entendimento de Oliveira (2017, p. 21), que aduz a interseccionalidade (interseccionalidade) ${ }^{15}$ como elemento para análise das múltiplas subalternizações.

\begin{abstract}
Outras imagens a que fui apresentada ao longo de minha trajetória escolar, e que muitas vezes me serviam de espelho, procuravam reproduzir as relações de poder que eram observadas em espaços variados, no Brasil e em outros países. Na maioria das vezes, a população negra era retratada de maneira subalternizada ou, então, reduzida à condição de escravizada, afirmando que os espaços nas sociedades ocidentais eram distribuídos a partir do pertencimento racial de cada pessoa ou de cada grupo de pessoas. Muitas dessas imagens ilustravam os livros didáticos, outras circulavam de outras formas: cartazes, revistas, jornais, novelas e programas humorísticos. Aquelas mais depreciativas da população negra e/ou homossexual eram usadas por colegas de escola, para lembrar que a minha cor era sinônimo de miséria, feiura, criminalidade e submissão e minha sexualidade uma doença contagiosa, portanto, minha companhia deveria ser evitada.
\end{abstract}

Como se pode perceber, o contexto de histórias de vida narrado a partir de produções acadêmicas de quatro (04) mulheres trans é capaz de elucidar como são construídas e reproduzidas as identidades de gênero (e sexuais) sem a menor possibilidade de escuta dessas vozes. O mais impactante é que este processo de silenciamento perdura durante toda a trajetória escolar. Mesmo na universidade, as redes de poder impedem a escuta, produzindo opacidade e invisibilidade das identidades trans.

Nestes contextos tão opressivos e de absoluta negação dessas vocalizações, as imagens produzidas pela HQ Minha professora é trans. E daí? tornam-se um elemento potente para reivindicar e demarcar as percepções dessas professoras quanto ao seu reconhecimento enquanto sujeitas de fala, autorizadas a serem escutadas em seus anseios, desejos e performatividades (BUTLER, 2012).

\footnotetext{
15 "Gosto de começar mencionando que a intersecionalidade pode servir de ponte entre diversas instituições e eventos e entre questões de gênero e de raça nos discursos acerca dos direitos humanos - uma vez que parte do projeto da intersecionalidade visa incluir questões raciais nos debates sobre gênero e direitos humanos e incluir questões de gênero nos debates sobre raça e direitos humanos." (CRENSHAW, 2012, p. 08).
} 


\section{CONSIDERAÇÕES FINAIS}

Inspiradoras histórias de vida como as de Marina Reidel (2013), Luma Nogueira de Andrade (2002), Letícia Lanz (2014) e Megg Rayara Gomes de Oliveira (2017) tecem novas possibilidades para compreender como as leituras e visões de mundo precisam abarcar as emergências de narrativas marginalizadas no cotidiano da escola (universidade), da ciência (investigações científicas), da literatura, das artes visuais e do conhecimento jurídico.

Relatar-se a si e aos outros produz uma intencionalidade relacional capaz de entender (ou pelo menos escutar) os possíveis significados (significações) desse "outro", dessa "outra" que está diante de mim ou de nós (sociedade). Empatia, alteridade ou simplesmente reconhecimento se traduzem em termos fundamentais para a construção de um novo humanismo ou para refundação da humanidade perdida ao largo da contemporaneidade.

Neste sentido, este estudo pretendeu vocalizar estas narrativas apresentadas na história em quadrinhos Minha professora é trans. E daí? e nos breves relatos das histórias de vida de Marina, Luma, Letícia e Megg. De caráter interdisciplinar, esta pesquisa qualitativa utilizou as imagens e os textos, procurando realizar uma bricolagem, como são utilizáveis os artefatos artísticos e culturais.

Ao campo do conhecimento jurídico coube suscitar em que medida o direito e, particularmente, o CONPEDI tem se constituído em um espaço de construção de novos diálogos, tendo como referências essas visualidades e esses contextos de vida.

Desta forma, espera-se que esta pesquisa possibilite aprofundar os diálogos interdisciplinares existentes entre arte e direito, bem como desvelar o reconhecimento identitário de pessoas trans. Intencionalizando um olhar cuidadoso, uma escuta atenta para essas histórias de vida, que nos circundam e nos produzem enquanto humanidade.

\section{REFERÊNCIAS}

ANDRADE. Luma Nogueira de. Travestis na escola: assujeitamento e resistência à ordem normativa. Tese (Programa de Pós-Graduação em Educação) - Universidade Federal do Ceará, UFC, Fortaleza, 2002. Disponível em:

http://www.repositorio.ufc.br/bitstream/riufc/7600/1/2012-TESE-LNANDRADE.pdf Acesso em: 17 abr. 2020. 
BENEVIDES, Bruna G. e NOGUEIRA, Sayonara Naider Bonfim (Orgs). Dossiê dos assassinatos e da violência contra travestis e transexuais brasileiras em 2019. São Paulo: Expressão Popular, ANTRA, IBTE, 2020. Disponível em:

https://antrabrasil.files.wordpress.com/2020/01/dossic3aa-dos-assassinatos-e-da-violc3aanciacontra-pessoas-trans-em-2019.pdf Acesso em: 17. Abr. 2020.

BENTO, Berenice. O que pode uma teoria? Estudos transviados e a despatologização das identidades trans. Revista Florestan, ano 1, n² 2, nov 2014, UFSCAR, São Carlos, SP: 2014.

CRENSHAW, Kimberle. A intersecionalidade na discriminação de raça e gênero.

Disponível em: http://www.acaoeducativa.org.br/fdh/wp-content/uploads/2012/09/KimberleCrenshaw.pdf Acesso: 17 abr. 2020.

DE MAIO, Alexandre. Minha professora é trans. E daí? Disponível em:

https://alexandredemaio.com.br/minha-professora-trans-e-dai-catraca-livre. Acesso em: 15 de abr. 2020.

DE MAIO, Alexandre. Minha professora é trans. E daí? Catraca Livre. Cidadania. 12 mar. 2015. Disponível em: https://catracalivre.com.br/cidadania/minha-professora-e-trans-e-dai/. Acesso em: 15 de abr. 2020.

DIAS, Renato Duro. Interdição de gênero: a lei que silencia o corpo. Revista Direito, Arte e Literatura, Minas Gerais, v.1, n.2, p. 229-245, jul./dez. CONPEDI, 2015.

EISNER, W. Quadrinhos e Arte Sequencial. São Paulo: Martins Fontes, 2001.

EISNER, W. Narrativas gráficas. São Paulo: Devir, 2005.

FAZENDA, Ivani. C. A. (Org.) Interdisciplinaridade: definição, projeto, pesquisa. In:

Práticas interdisciplinares na escola. 11 ed. São Paulo: Cortez, 2009.

LANZ, Letícia. O corpo da roupa a pessoa transgênera entre a transgressão e a conformidade com as normas de gênero. Dissertação (Programa de Pós-Graduação em Sociologia) - Universidade Federal do Paraná, Curitiba, 2014. Disponível em: https://acervodigital.ufpr.br/bitstream/handle/1884/36800/R\%20-\%20D\%20\%20LETICIA\%20LANZ.pdf. Acesso em: 17 de abr. 2020.

LIMA, Fátima. Produções e Experiências “Trans"- saber, poder e subversão. In: Corpos, Gêneros, Sexualidades: Política de Sujetivação; textos reunidos. (Org.): LIMA, Fátima. $2^{\text {a }}$ ed. Porto Alegre: Rede Unida, 2014.

MARCHI, Giulia. Conheça essas incríveis histórias em quadrinhos LGBTQ. Disponível: https://www.revolutionnow.com.br/conheca-essas-incriveis-historias-em-quadrinhoslgbtq/?fbclid=IwAR3O43k1_LrYUveU5BJFzsmkSU3_z5a9SK_8w0QJrxxC25uz777KTy1iU uo . Acesso em: 15 abr. 2020.

MIGUEL, Luis Felipe. Ainda sobre o papel do "lugar de fala". 07 ago. 2019. Disponível em: https://esquerdaonline.com.br/2019/08/07/luis-felipe-miguel-ainda-sobre-o-papel-do- 
lugar-de-fala/. Acesso em: 12 abr. 2020.

OLIVEIRA. Megg Rayara Gomesde. O diabo em forma de gente: (r)existências de gays afeminados, viados e bichas pretas na educação. Tese (Programa de Pós-Graduação em Educação) - Universidade Federal do Paraná, UFPR, Curitiba, 2017. Disponível em: https://acervodigital.ufpr.br/bitstream/handle/1884/47605/R\%20-\%20T\%20\%20MEGG\%20RAYARA\%20GOMES\%20DE\%20OLIVEIRA.pdf?sequence $=1 \&$ isAllowed =y. Acesso em: 17 de abr 2020.

REIDEL, Marina. A pedagogia do salto alto: histórias de professoras transexuais e travestis na educação brasileira. Dissertação (Programa de Pós-Graduação em Educação) Universidade Federal do Rio Grande do Sul, UFRGS, Porto Alegre, 2013. Disponível em: https://www.lume.ufrgs.br/handle/10183/98604 . Acesso em: 17 de abr. 2020.

RIBEIRO, Djamila. O que é lugar de fala? Belo Horizonte, MG: Letramento, Justificando, 2017.

SMEE, Guilherme. Artistas Transexuais dos Comics Que Você Precisa Conhecer. 22 ju, 2018. Disponível em: https://splashpages.wordpress.com/2018/06/22/artistas-transexuais-doscomics-que-voce-precisaconhecer/?fbclid=IwAR387zTpleEnHErTRMvAIIDCfdCE2vHHAfqmvpH52XN4TIDCQkjY RmmrzjY . Acesso em: 15 abr. 2020.

SPIVAK, Gayatri Chakravorty. Pode o subalterno falar? Belo Horizonte: Editora UFMG, 2014.

TAVARES, Mayara Barbosa. História em quadrinhos não ficcionais: usos e discursos. Tese (Doutorado em Letras e Linguística) - Universidade Federal de Goiás, Goiânia, 2016. Disponível em: https://repositorio.bc.ufg.br/tede/handle/tede/6540?mode=full . Acesso em: 17 abr. 2020.

UNESCO. Organização das Nações Unidas para a educação, a ciência e a cultura.

Interdisciplinarité dans l'enseignement general. Division des sciences de l'éducation, des contenus et des méthodes. Bruxelas, Bélgica: UNESCO, 1986. Disponível em: https://en.unesco.org/themes/education/. Acesso em: 12 abr. 2020. 